\title{
(2) OPEN ACCESS \\ Association of clinical competence, specialty and physician country of origin with opioid prescribing for chronic pain: a cohort study
}

\author{
Robyn Tamblyn (1), ${ }^{1}$ Nadyne Girard, ${ }^{2}$ John Boulet, ${ }^{3}$ Dale Dauphinee, ${ }^{3,4}$ \\ Bettina Habib (1) ${ }^{2}$
}

- Additional supplemental material is published online only. To view, please visit the journal online (http://dx.doi. org/10.1136/bmjas-2021013503).

For numbered affiliations see end of article.

\section{Correspondence to}

Dr Robyn Tamblyn, Department of Medicine and Department of Epidemiology and Biostatistics, McGill University, Montreal, Quebec H3A 1A3, Canada; robyn.tamblyn@mcgill.ca

Received 12 April 2021 Accepted 31 August 2021

\section{SLinked}

- http://dx.doi.org/10.1136/ bmjqs-2021-013697

\section{Check for updates}

(c) Author(s) (or their employer(s)) 2021. Re-use permitted under CC BY-NC. No commercial re-use. See rights and permissions. Published by BMJ.

To cite: Tamblyn R, Girard N, Boulet J, et al. BMJ Qual Saf Epub ahead of print: [please include Day Month Year]. doi:10.1136/

bmjqs-2021-013503

\begin{abstract}
Background Although little is known about why opioid prescribing practices differ between physicians, clinical competence, specialty training and country of origin may play a role. We hypothesised that physicians with stronger clinical competence and communication skills are less likely to prescribe opioids and prescribe lower doses, as do medical specialists and physicians from Asia. Methods Opioid prescribing practices were examined among international medical graduates (IMGs) licensed to practise in the USA who evaluated Medicare patients for chronic pain problems in 2014-2015. Clinical competence was assessed by the Educational Commission for Foreign Medical Graduates (ECFMG) Clinical Skills Assessment. Physicians in the ECFMG database were linked to the American Medical Association Masterfile. Patients evaluated for chronic pain were obtained by linkage to Medicare outpatient and prescription files. Opioid prescribing was measured within 90 days of evaluation visits. Prescribed dose was measured using morphine milligram equivalents (MMEs). Generalised estimating equation logistic and linear regression estimated the association of clinical competence, specialty, and country of origin with opioid prescribing and dose.

Results 7373 IMGs evaluated 65012 patients for chronic pain; $15.2 \%$ received an opioid prescription. Increased clinical competence was associated with reduced opioid prescribing, but only among female physicians. For every $10 \%$ increase in the clinical competence score, the odds of prescribing an opioid decreased by $16 \%$ for female physicians (OR 0.84 , $95 \% \mathrm{Cl} 0.75$ to 0.94 ) but not male physicians (OR $0.99,95 \% \mathrm{Cl} 0.92$ to 1.07$)$. Country of origin was associated with prescribed opioid dose; US and Canadian citizens prescribed higher doses (adjusted MME difference +3.56 ). Primary care physicians were more likely to prescribe opioids, but surgical and hospital-based specialists prescribed higher doses.

Conclusions Clinical competence at entry into US graduate training, physician gender, specialty and country of origin play a role in opioid prescribing practices.
\end{abstract}

\section{INTRODUCTION}

The USA is in the midst of an opioid epidemic, with the highest rate of opioid consumption in the world. ${ }^{1-4}$ Initially fuelled by a threefold increase in opioid prescribing rates from 1990 to $2012,{ }^{5}$ physicians and state regulatory authorities responded by lowering both prescribing rates and quantities. ${ }^{6-8}$ Of interest, although the monthly incidence of new opioid prescriptions fell by $54 \%$ by 2017 , along with the number of prescribing physicians, the subgroup of physicians who continued to prescribe opioids were more likely to initiate opioid therapy at higher doses and for longer duration. ${ }^{9}$

Little is known about why opioid prescribing practices vary among physicians. A recent study noted that surgeons with less experience were more likely to prescribe higher opioid doses, ${ }^{10}$ which may be related to the common complaint that current training programmes do not provide sufficient education in pain management. ${ }^{11}$ The finding that physicians graduating from the top 10 medical schools in the USA were less likely to prescribe opioids strengthens the possibility that differences in training and clinical decision-making may be contributing to varying opioid prescribing practices. ${ }^{12}$ An intriguing study of dentists in the USA and UK found a 37-fold difference in opioid prescribing following dental procedures: $0.05 \%$ among UK dentists compared with $3.5 \%$ among US dentists. ${ }^{13}$ An international study of common lowrisk surgical procedures also showed striking differences, with $91 \%$ of patients in the USA receiving postoperative opioid prescriptions vs $5 \%$ of patients not in the USA. ${ }^{14}$ While these differences may be due to training, there is also the possibility of differences in cultural expectations for pain management. It has been noted that 
the creation of pain as the fifth vital sign in the USA promoted an expectation that all pain was to be eliminated. ${ }^{15} 16$ In contrast, in countries such as Japan, the Philippines and England, stoicism toward pain is both valued and expected. ${ }^{17-21}$

We had a unique opportunity to evaluate the contribution of clinical competence, country of origin, training location and specialty to opioid prescribing for chronic non-cancer pain. We examined opioid prescribing in a cohort of international medical graduates (IMGs) from over 700 medical schools and 100 countries who were licensed to practise in the USA after passing the required Clinical Skills Assessment (CSA) examination. ${ }^{22}$ We evaluated opioid prescribing practices in the period after 2012, when stricter controls were implemented to restrict opioid prescribing, with the aim of identifying the characteristics of physicians who continued to prescribe to opioids for non-cancerrelated chronic pain and at higher doses. Prior research on performance-based examinations has shown that examination scores are associated with quality of care even after 12 years in practice. ${ }^{23-25}$ We hypothesised that physicians with stronger clinical and communication skills are less likely to prescribe opioids and prescribed them at lower doses, as do medical specialists and physicians from Asia, associations that may be modified by physician age and gender due to differing practice characteristics. ${ }^{26-31}$

\section{METHODS}

\section{Design}

IMGs who completed the Educational Commission for Foreign Medical Graduates (ECFMG) CSA between 1998 and 2004 and saw one or more US Medicare patients for common chronic pain conditions in 2014-2015 were assessed with respect to use of opioids for pain management.

\section{Physician population}

Physicians were eligible if they were licensed to practise in at least one jurisdiction in the USA, were in active practice, billed the Centre for Medicare and Medicaid Services (CMS) for at least one patient in 2014-2015, and conducted an evaluation in an ambulatory setting of patient(s) they diagnosed as having a common chronic pain problem. Physicians identified in ECFMG CSA examination files were linked to the American Medical Association (AMA) Physician Masterfile by first and last name, sex, and date of birth and then to the National Plan and Provider Enumeration System to obtain National Provider Identifiers (NPIs), specialty, type of practice and current location. Once linked, nominal data were deleted to protect confidentiality. Physician NPIs were sent to the CMS, who identified all patients seen by these physicians in 2014-2015 in the Medicare Carrier RIF file, inpatient files, outpatient file and Part D files, and then all services provided to these patients by any health professional.

\section{Patient population}

Opioids are generally not recommended for chronic non-cancer pain, ${ }^{32-34}$ of which the most common problems are back and neck pain, ${ }^{35-37}$ migraine/headache, ${ }^{3637}$ osteoarthritis or rheumatoid arthritis, ${ }^{35-37}$ and neuropathic-related pain disorders. ${ }^{35} 37$ To assess opioid prescribing practices, we assembled all patients who had one of these pain problems. To be included, patients had to have had an ambulatory evaluation visit with a study physician between June 2014 and September 2015 for which the physician submitted a billing diagnosis for one of the respective pain conditions, and been covered during this period in the Medicare Part D drug insurance programme. We excluded inpatients, visits for procedure-related treatments and consultation visits as the respective physician may not have provided ongoing management for the patient's condition. We also excluded patients who had received an opioid prescription from another physician in the 6 months prior to the evaluation visit, and those covered by CMS for endstage renal failure. Previously validated International Classification of Disease versions 9-10 Clinical Modification codes were used to identify each common chronic pain problem ${ }^{38}$ (online supplemental etable 1). If patients saw multiple study physicians, only the visit with the first physician was included.

\section{Clinical competence}

The CSA examination administered by the ECFMG between 1998 and 2004 was used as a measure of clinical competence. Modelled after the Canadian national standardised clinical licensing examination, ${ }^{22} 3940$ it was put in place to ensure that all IMGs could demonstrate a level of clinical skills necessary for entry into US graduate medical education programmes. In 2004, it was transferred to the National Board of Medical Examiners as USMLE Step 2 Clinical Skills, and became a requirement for medical licensure for graduates of all US and foreign medical schools. ${ }^{40-42}$ The CSA consisted of 10 or 11 modelled encounters between the candidate and a standardised patient. An overall clinical competence score was given based on history taken and physical examination conducted in these encounters and each candidate's diagnosis and management plan as written in a post-encounter clinical note. Candidates' interpersonal skills were assessed in each encounter by the standardised patient, as was their spoken English proficiency. Ratings from each encounter were pooled to form a doctor-patient communication composite (COM) score. Acceptable clinical competence and COM scores were both required to pass the examination. First time scores and the 
number of attempts to pass the examination were assessed in relationship to opioid prescribing.

\section{Country of origin and training location}

While there is no direct measure of cultural expectations for pain management, we anticipated that a physician's country of origin and/or location of training may reflect these expectations. We measured geographical location of medical training, as well as citizenship at the time of training. Training location was categorised as Asia, Europe, India/Pakistan, the Middle East, Central, South America and the Caribbean, and other. Citizenship was categorised as Asia, Europe, India/Pakistan, Middle East, USA/Canada and other, and was documented at the time of medical school entry.

\section{Specialty}

Certain specialties, namely primary care physicians, orthopaedic surgeons, pain specialists and emergency medicine physicians, are more likely to prescribe opioids, ${ }^{43-46}$ possibly due to patient mix. Specialty designation retrieved from the National Plan and Provider Enumeration System was grouped into the following categories based on the CMS classification (online supplemental etable 2): primary care, internal medicine, medical specialty, surgical specialty, hospitalbased specialty and other. While internal medicine is often included in primary care, a large number of physicians in the cohort were trained in general practice, family medicine and internal medicine; and as differences in quality of care have been documented for internal medicine physicians compared with other primary care physicians, we kept these groups separate. $^{47-51}$

\section{Opioid prescribing practices}

At the patient level, we measured whether an opioid had been prescribed by the study physician, defined as a dispensing of an opioid prescribed by the study physician within 90 days of the evaluation visit. Opioids included buprenorphine, codeine, fentanyl, hydrocodone, hydromorphone, meperidine, morphine, oxycodone, oxymorphone, pentazocine and tramadol. Opioid prescribing guidelines for chronic noncancer pain indicate that an opioid may be appropriate if non-opioid analgesics and/or physiotherapy/ chiropractic treatment has failed. ${ }^{33} 345253$ We used prescription drug event files and claims from institutional (outpatient) and non-institutional providers to measure whether patients had received a dispensed prescription for non-steroidal anti-inflammatory drugs (Anatomic Therapeutic Classification M01A) or physiotherapy/chiropractic treatment prior to the opioid prescription, and adjusted for this in the analysis. Among patients prescribed an opioid, we measured the prescribed daily dose using morphine milligram equivalents (MMEs) to enable comparisons among opioids. MME/day was defined as the prescribed daily dose multiplied by the equivalent analgesic ratio of the opioid type as specified by the Centre for Disease Control and Prevention. ${ }^{54}$

\section{Physician and patient covariates}

As male physicians and younger physicians are more likely to prescribe opioids, ${ }^{55-58}$ we adjusted for these characteristics using demographic information from the ECFMG database. We also adjusted for the US census classification for practice region (South, West, Northeast, Midwest), as higher rates of opioid use are noted in southern US regions. ${ }^{4659}$

To address potential differences in case mix between physicians that may influence opioid prescribing, we measured patient sex, age and type of medicare plan (65 years and older or CMS disability coverage). To account for differences in severity and complexity of patients' conditions, we measured whether there was an emergency department (ED) visit or hospitalisation in the 6 months prior to the evaluation visit, the presence of the 30 conditions included in the Elixhauser Comorbidity Index, the type of pain problem, and whether the evaluation visit occurred in the ED or an office/clinic setting. ${ }^{60-64}$ To determine patients' probabilities of receiving an opioid prescription based on their characteristics, we estimated the association between patient characteristics and the likelihood of receiving an opioid prescription using logistic regression within a generalised estimating equation (GEE) framework to account for clustering by physician. OR estimates for each characteristic were used to create a probability of receiving an opioid score for each patient. The same approach with multiple linear GEE regression was used to estimate MME dose among patients prescribed an opioid.

\section{Analysis}

Descriptive statistics were used to summarise physician and patient characteristics. To estimate the association of clinical competence, citizenship, training location and specialty with the risk of opioid prescribing, we used GEE logistic regression. Patient was the unit of analysis and physicians were the clustering factor, accounted for using an exchangeable correlation coefficient. Each CSA score (clinical competence, communication) and its respective subscores (history and physical examination, diagnosis and management, interpersonal skills, English proficiency) were fit in a separate model as a continuous variable, with citizenship included as dummy variables using Asia as the reference category, as it was one of the largest groups and enabled more stable estimates. As citizenship and medical school location were highly correlated (ie, collinear), we could not estimate the independent contribution of each to the outcome. Therefore, we assessed which one was the better predictor of opioid prescribing, using the penalised quasi-likelihood under the independence 
model criterion to determine the best fitting model. We also included a binary indicator representing whether the physician passed their first examination attempt. All models were adjusted for physician age and gender, location and region of practice, whether physiotherapy/chiropractic services or non-steroidal anti-inflammatory drugs had been provided prior to an opioid dispensation, and the patient's probability of receiving an opioid prescription. As there are known differences in practice patterns of male and female physicians and younger and older physicians, ${ }^{55-58}$ we assessed whether the impact of clinical competence or country of origin/medical school location on opioid prescribing was modified by physician gender or age by fitting the respective two-way interaction terms. The same approach with dose modelled as a continuous variable using multiple linear GEE regression was used for the investigation of physician characteristics and opioid dose, among patients who received an opioid prescription. To facilitate interpretation of findings for clinical competence, we plotted the probability of opioid prescribing and predicted dose, and 95\% CIs, per $10 \%$ increase in clinical competence, based on the models. The potential impact of multiple comparisons was assessed using the Bonferroni correction. All analyses were done using SAS V.9.4.

\section{RESULTS}

Overall, 7373 IMGs passed the ECFMG CSA, achieved ECFMG certification, received a license to practise in the USA and billed an evaluation visit for at least one patient with a common chronic pain problem in an ambulatory setting in 2014-2015. Of the 32886 physicians who took the CSA examination, 20.5\% were not linked to the AMA file either because they did not apply for a license to practise or could not be linked. Compared with physicians who were found in the AMA files, the CSA scores of those not found were equivalent (linked vs not linked: mean \pm SD clinical competence score: $65.0 \pm 5.3$ vs $65.0 \pm 5.5$; communication score: $78.0 \pm 7.8$ vs $77.5 \pm 7.9)$. Most of the 7373 study physicians were male (61.1\%), with an average age of 43.5 years in 2014 (table 1). At entry into medical school, $53.4 \%$ were citizens of India/ Pakistan (30.3\%) or the USA/Canada (23.1\%). Over one-third attended medical school in Central/South America, Mexico or the Caribbean (36.0\%), 75.8\% of whom were US citizens. Most physicians specialised in primary care $(35.6 \%)$ or internal medicine $(32.1 \%)$, and over one-third practised in the southern USA (35.8\%). On the first attempt, $85.9 \%$ of physicians passed the CSA. The overall mean clinical competence score was $64.6 \%$. The highest examination scores were in communication (78.1\%) and its two component subscores, English proficiency (85.4\%) and interpersonal skills $(76.5 \%)$. The lowest scores were in diagnosis and management (59.5\%).

Overall, 65012 patients were evaluated and diagnosed by study physicians with one of the four common pain problems, the most common being back, neck and/or lumbar pain (70.3\%) (table 2). Of these patients, $9870(15.2 \%)$ were prescribed and

Table 1 Characteristics of the 7373 international medical graduate physicians who billed Medicare for an evaluation visit in an ambulatory setting for patients with common chronic pain problems

\begin{tabular}{|c|c|c|c|c|c|}
\hline Characteristic & Number & $\%$ & Characteristic & Number & $\%$ \\
\hline Physician gender & & & Internal medicine & 2364 & 32.1 \\
\hline Female & 2867 & 39.0 & Medical specialty & 951 & 12.9 \\
\hline Male & 4506 & 61.0 & Surgery specialty & 326 & 4.4 \\
\hline Citizenship & & & Hospital-based specialty & 644 & 8.7 \\
\hline Asia & 948 & 12.9 & Emergency medicine & 464 & 6.3 \\
\hline Europe & 840 & 11.4 & Region of practice & & \\
\hline India and Pakistan & 2233 & 30.3 & Northeast & 1727 & 23.4 \\
\hline Middle East & 610 & 8.3 & Midwest & 1511 & 20.5 \\
\hline Other & 1036 & 14.0 & South & 2641 & 35.8 \\
\hline USA and Canada & 1706 & 23.1 & West & 1494 & 20.3 \\
\hline Medical school location & & & Clinical Skills Assessment proficiency & Mean & SD \\
\hline Asia & 755 & 10.2 & Passed assessment on first attempt & 6330 & 85.85 \\
\hline Europe & 978 & 13.3 & Physician age & 43.5 & 5.5 \\
\hline India and Pakistan & 2018 & 27.4 & & Mean & SD (range) \\
\hline Middle East & 506 & 6.9 & Clinical competence score & 64.6 & $5.4(37-85)$ \\
\hline $\begin{array}{l}\text { Central America/Caribbean/Mexico/ } \\
\text { South America }\end{array}$ & 2667 & 36.0 & History and physical examination & 68.1 & $6.8(35-89)$ \\
\hline Other & 449 & 6.1 & Diagnosis and management & 59.5 & $9.5(22-95)$ \\
\hline Physician specialty & & & Communication & 78.1 & $8.1(40-98)$ \\
\hline \multirow[t]{2}{*}{ Primary care } & 2624 & 35.6 & English proficiency & 85.4 & $14.5(29.5-100)$ \\
\hline & & & Interpersonal skills & 76.5 & $7.8(44-100)$ \\
\hline
\end{tabular}


Table 2 The association between patient characteristics and the odds of being prescribed an opioid and the morphine milligram equivalent (MME) dose of opioid prescribed

\begin{tabular}{|c|c|c|c|c|c|c|c|c|}
\hline \multirow[b]{2}{*}{ Characteristic } & \multicolumn{4}{|c|}{ Odds of prescribing an opioid for the 65012 patients } & \multicolumn{4}{|c|}{$\begin{array}{l}\text { MME opioid dose prescribed for the } 9870 \text { patients who } \\
\text { received an opioid prescription }\end{array}$} \\
\hline & $\begin{array}{l}N \text { patients } \\
(\%)\end{array}$ & $\begin{array}{l}N \text { patients } \\
\text { with opioid } \\
(\%)\end{array}$ & OR $(95 \% \mathrm{Cl})$ & $P$ value & N patients (\%) & Mean (SD) & $\begin{array}{l}\text { Estimated } \\
\text { difference }(95 \% \mathrm{Cl})\end{array}$ & $P$ value \\
\hline \multicolumn{9}{|l|}{ Type of chronic pain problem } \\
\hline Migraine, headache & $7348(11.3)$ & $509(6.9)$ & $0.3(0.30$ to 0.36$)$ & $<0.001$ & $509(5.2)$ & $22.5(15.2)$ & $-3.6(-5.2$ to -2.0$)$ & $<0.001$ \\
\hline Neuropathic pain disorders & $4682(7.2)$ & $513(11.0)$ & $0.6(0.49$ to 0.61$)$ & $<0.001$ & $513(5.2)$ & $38.1(54.2)$ & $10.4(2.8$ to 18.1$)$ & 0.007 \\
\hline Osteo-rheumatoid pain & $7253(11.2)$ & $449(6.2)$ & $0.4(0.35$ to 0.46$)$ & $<0.001$ & $449(4.5)$ & $21.9(28.1)$ & $-2.5(-5.3$ to 0.3$)$ & 0.080 \\
\hline Back, neck lumbar pain & $45729(70.3)$ & $8399(18.4)$ & Reference & & $8399(85.1)$ & $27.3(36.2)$ & Reference & \\
\hline \multicolumn{9}{|l|}{ Sex } \\
\hline Female & $42644(65.6)$ & $6203(14.5)$ & Reference & & $6203(62.8)$ & $25.9(33.4)$ & Reference & \\
\hline Male & $22368(34.4)$ & $3667(16.4)$ & $1.0(0.97$ to 1.06$)$ & 0.506 & $3667(37.2)$ & $30.0(40.7)$ & $2.3(0.8$ to 3.9$)$ & 0.003 \\
\hline \multicolumn{9}{|l|}{ Race } \\
\hline Asian & $2966(4.6)$ & $320(10.8)$ & $0.8(0.72$ to 0.92$)$ & 0.001 & $320(3.2)$ & $21.1(27.0)$ & $-2.6(-6.5$ to 1.3$)$ & 0.190 \\
\hline Black & $6777(10.4)$ & $1081(16.0)$ & $0.9(0.85$ to 0.99$)$ & 0.035 & $1081(11.0)$ & $29.4(39.2)$ & $-5.1(-9.3$ to -0.9$)$ & 0.017 \\
\hline Hispanic & $3553(5.5)$ & $430(12.1)$ & 0.8 (0.69 to 0.85$)$ & $<0.001$ & $430(4.4)$ & $23.4(36.5)$ & $-3.5(-6.8$ to -0.3$)$ & 0.032 \\
\hline North American Native & $228(0.4)$ & $36(15.8)$ & 0.9 (0.64 to 1.35$)$ & 0.695 & $36(0.4)$ & $29.6(58.5)$ & $2.6(-13.2$ to 18.4$)$ & 0.745 \\
\hline Other race & $2542(3.9)$ & $301(11.8)$ & $0.8(0.72$ to 0.90$)$ & $<0.001$ & $301(3.0)$ & $23.3(25.6)$ & $-3.1(-6.7$ to 0.5$)$ & 0.090 \\
\hline White & $48946(75.3)$ & $7702(15.7)$ & Reference & & $7702(78.0)$ & $27.8(36.4)$ & Reference & \\
\hline \multicolumn{9}{|l|}{ Insurance group } \\
\hline $65+$ & $51631(79.4)$ & $7395(14.3)$ & Reference & & $7395(74.9)$ & $23.3(23.6)$ & Reference & \\
\hline Disabled & $13381(20.6)$ & $2475(18.5)$ & 1.3 (1.18 to 1.39$)$ & $<0.001$ & $2475(25.1)$ & $39.6(58.4)$ & 8.2 (4.6 to 11.7 ) & $<0.001$ \\
\hline \multicolumn{9}{|c|}{ Evaluation visit was in the emergency } \\
\hline Yes & $4638(7.1)$ & $1092(23.5)$ & $1.7(1.59$ to 1.93$)$ & $<0.001$ & $1092(11.1)$ & $29.1(14.0)$ & $5.1(3.6$ to 6.6$)$ & $<0.001$ \\
\hline No & $60374(92.9)$ & $8778(14.5)$ & Reference & & $8778(88.9)$ & $27.2(38.2)$ & Reference & \\
\hline \multicolumn{9}{|c|}{ Acute care in the 6 months pre-evaluation } \\
\hline Emergency department visit & $19379(29.8)$ & $2996(15.5)$ & $1.0(0.92$ to 1.02$)$ & 0.262 & $2996(30.4)$ & $26.9(35.7)$ & $-0.6(-2.4$ to 1.2$)$ & 0.528 \\
\hline $\begin{array}{l}\text { No emergency department } \\
\text { visit }\end{array}$ & $45633(70.2)$ & $6874(15.1)$ & Reference & & $6874(69.6)$ & $27.6(36.6)$ & Reference & \\
\hline Hospitalisation & $7630(11.7)$ & $1202(15.8)$ & 1.1 (1.05 to 1.22$)$ & 0.002 & $1202(12.2)$ & $28.1(35.1)$ & $5.3(2.8$ to 7.7$)$ & $<0.001$ \\
\hline No hospitalisation & $57382(88.3)$ & $8668(15.1)$ & Reference & & $8668(87.8)$ & $27.3(36.5)$ & Reference & \\
\hline $\begin{array}{l}\text { Age at evaluation visit (per } \\
10 \text { years) }\end{array}$ & & & $1.0(0.98$ to 1.03$)$ & 0.663 & & & $-1.6(-2.6$ to -0.5$)$ & 0.003 \\
\hline 20-65years old & $16456(25.3)$ & $3118(18.9)$ & & & $3118(31.6)$ & $38.6(56.0)$ & & \\
\hline $66-70$ years old & $14807(22.8)$ & $2028(13.7)$ & & & $2028(20.5)$ & $24.6(24.1)$ & & \\
\hline $71-80$ years old & $20970(32.3)$ & $2848(13.6)$ & & & $2848(28.9)$ & $22.0(16.2)$ & & \\
\hline More than 80 years old & $12779(19.7)$ & $1876(14.7)$ & & & $1876(19.0)$ & $20.1(20.0)$ & & \\
\hline
\end{tabular}

filled an opioid prescription written by the study physician. The majority were prescribed hydrocodone $(37.0 \%)$ or tramadol $(34.1 \%)$ (online supplemental etable 3). Patient characteristics associated with a significantly increased risk of receiving an opioid prescription included being insured because of disability, the evaluation visit being conducted in the ED and a hospitalisation having occurred in the 6 months prior to the evaluation visit (table 2). Patients who presented with migraine, neuropathic, or arthritic pain had a significantly lower risk of receiving an opioid compared with those with back or neck pain, as were patients from any other race compared with white. Patients with pre-existing psychoses, collagen disease or neurological disorders were also less likely to receive an opioid (online supplemental etable 4). The overall mean prescribed MME dose was 27.4 (SD
36.3). Significantly higher doses were prescribed for patients with neuropathic pain disorders compared with back pain, patients who were insured because of disability, patients whose evaluation visit was in the $\mathrm{ED}$ and patients who were hospitalised in the past 6 months. Lower doses were prescribed to black patients and Hispanics compared with white patients, to older patients, and to patients with pre-existing chronic pulmonary disease or HIV/AIDs (table 2, online supplemental etable 4).

The association between clinical competence and opioid prescribing was significantly modified by physician gender, but not by age or citizenship. For every $10 \%$ increase in the clinical competence score, the odds of prescribing an opioid significantly decreased by $16 \%$ (OR $0.84,95 \%$ CI 0.75 to 0.94 ) for female physicians but not for male physicians (OR 0.99, 95\% 
Table 3 The association between clinical competence scores, the odds of opioid prescribing and prescribed morphine milligram equivalent (MME) dose by physician gender per 10\% increase in score

\begin{tabular}{|c|c|c|c|c|}
\hline \multirow[b]{2}{*}{ Scorexgender interaction } & \multicolumn{2}{|c|}{$\begin{array}{l}\text { Odds of prescribing an opioid for the } 65012 \\
\text { patients }\end{array}$} & \multicolumn{2}{|c|}{$\begin{array}{l}\text { MME opioid dose prescribed for the } 9870 \\
\text { patients }\end{array}$} \\
\hline & OR $(95 \% \mathrm{Cl})$ & $P$ value & Estimate $(95 \% \mathrm{Cl})$ & $P$ value \\
\hline \multicolumn{5}{|l|}{ Clinical competence score } \\
\hline Male & 0.99 (0.92 to 1.07$)$ & 0.7889 & $0.60(-1.26$ to 2.46$)$ & 0.5272 \\
\hline Female & $0.84(0.75$ to 0.94$)$ & 0.0019 & $-1.37(-3.94$ to 1.20$)$ & 0.2965 \\
\hline \multicolumn{5}{|l|}{ History and physical examination } \\
\hline Male & 0.99 (0.93 to 1.05) & 0.6600 & $0.50(-1.28$ to 2.29$)$ & 0.5820 \\
\hline Female & $0.92(0.84$ to 1.00$)$ & 0.0511 & $-0.95(-3.03$ to 1.13$)$ & 0.3724 \\
\hline \multicolumn{5}{|l|}{ Diagnosis and management } \\
\hline Male & 0.99 (0.95 to 1.03$)$ & 0.5237 & 1.05 (0.01 to 2.09) & 0.0482 \\
\hline Female & 0.92 (0.86 to 0.98$)$ & 0.0102 & $-0.92(-2.37$ to 0.53$)$ & 0.2120 \\
\hline \multicolumn{5}{|l|}{ Communication score } \\
\hline Male & 1.01 (0.96 to 1.07$)$ & 0.6387 & $1.23(-0.08$ to 2.54$)$ & 0.0651 \\
\hline Female & 0.90 (0.84 to 0.97$)$ & 0.0062 & $0.69(-1.11$ to 2.49$)$ & 0.4519 \\
\hline \multicolumn{5}{|l|}{ English proficiency } \\
\hline Male & 1.00 (0.97 to 1.03$)$ & 0.9340 & $0.43(-0.43$ to 1.29$)$ & 0.3273 \\
\hline Female & $0.97(0.93$ to 1.01$)$ & 0.1715 & $0.28(-0.82$ to 1.38$)$ & 0.6216 \\
\hline \multicolumn{5}{|l|}{ Interpersonal skills } \\
\hline Male & 1.03 (0.97 to 1.08$)$ & 0.3493 & $0.99(-0.36$ to 2.34$)$ & 0.1523 \\
\hline Female & 0.91 (0.85 to 0.98$)$ & 0.0123 & $-0.10(-1.84$ to 1.65$)$ & 0.9152 \\
\hline
\end{tabular}

Models were adjusted for physician's gender, citizenship, specialty, region of practice, age, prescribed physio-NSAID before opioid, score and patient confounder score.

$P$ value for gender $\times$ clinical competence score interaction opioid prescription: $0.04 ; p$ value for gender $\times$ communication score opioid prescription: $0.009 ; p$ value for genderxdiagnosis and management score and MME dose: 0.03 . NSAID, non-steroidal anti-inflammatory drug.

CI 0.92 to 1.07 ) (table 3 ; figure $1 \mathrm{~A}$ ). A significant reduction of $8 \%$ in the odds of prescribing an opioid per $10 \%$ increase in score was also found for female physicians for the two clinical competence subscores: history and physical examination (OR 0.92, 95\% CI 0.84 to 1.00$)$ and diagnosis and management (OR $0.92,95 \%$ CI 0.86 to 0.98 ). Similarly, a $10 \%$ increase in communication score was associated with a significant $10 \%$ reduction in the odds of opioid prescribing for female physicians (OR $0.90,95 \%$ CI 0.84 to 0.97 ) but not male physicians (OR 1.01, 95\% CI 0.96 to 1.07), a finding predominantly related to competence in interpersonal skills rather than English proficiency. Among the 3675 physicians who prescribed an opioid, clinical competence was not associated with the dose prescribed with the exception of competence in diagnosis and management: a 10\% increase in score was associated with a significant increase in dose of 1.05 MME (95\% CI 0.01 to 2.09) prescribed by male physicians, but had the opposite effect of lower prescribed doses for female physicians, although the latter was not significant. If the $\mathrm{p}$ value were corrected for multiple comparisons, the association between clinical competence and dose prescribed would not be statistically significant.

Physician citizenship provided a better fitting model than medical school location so it was used in all models. While the proportion of patients receiving an opioid prescription was highest for US/Canadian citizens $(17.5 \%$ vs $12.5 \%-15.6 \%$ for physicians from other countries), physician citizenship was not significantly associated with the odds of prescribing, after adjusting for other physician and patient characteristics (table 4). However, US and Canadian physicians prescribed opioids at significantly higher doses (mean MME 31.5) compared with physicians from Asia (mean MME 25.1: adjusted difference 3.56, 95\% CI 0.70 to 6.42 ). The main difference was in drug choice, with US/Canadian physicians more likely to prescribe oxycodone $(16.3 \%$ vs $10.5 \%)$ and less likely to prescribe codeine (6.6\% vs $11.8 \%)$ than Asian physicians (online supplementary etable 3 ).

Male physicians were $11 \%$ more likely to prescribe an opioid (OR 1.11, 95\% CI 1.03 to 1.19) and prescribed it at higher doses compared with female physicians (mean MME dose 29.1 vs 22.8 ; adjusted mean difference $2.60,95 \%$ CI 0.90 to 4.31 ). Physician age was not associated with the odds of opioid prescribing, but older physicians prescribed moderately higher doses (per 10 years, adjusted MME dose increase $1.82,95 \% \mathrm{CI}-0.03$ to 3.67 ). The majority of opioids were prescribed by primary care physicians, internal medicine or hospital-based specialists. Compared with primary care physicians, physicians in all other specialties, except hospital-based specialties, were less likely to prescribe opioids, particularly 


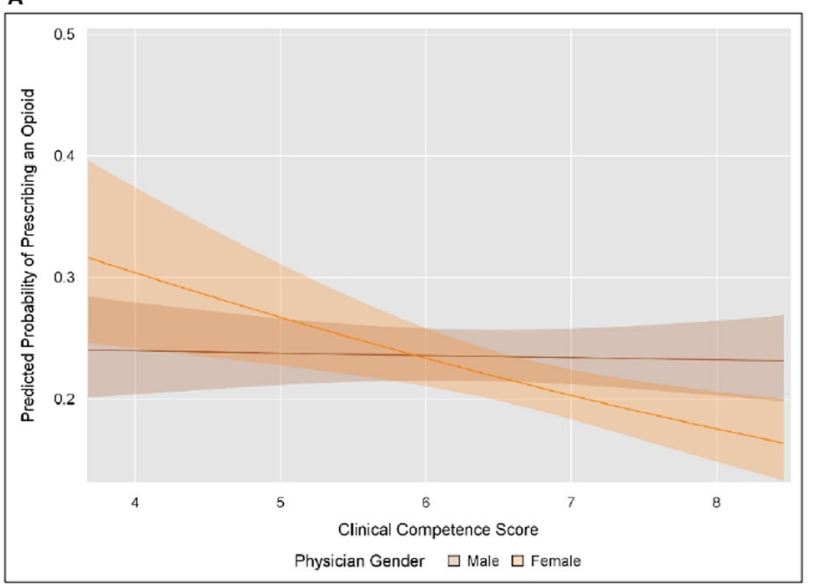

B

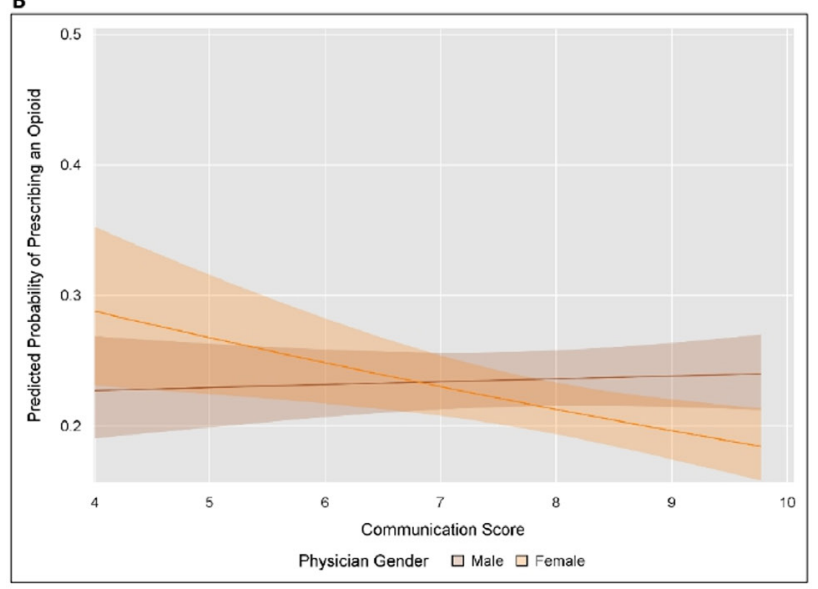

C

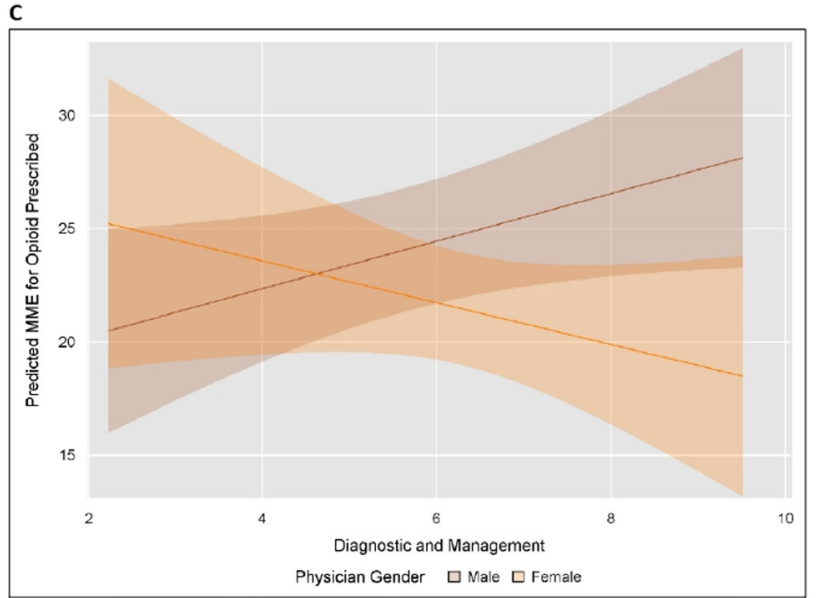

Figure 1 The association between Clinical Skills Assessment scores and the predicted probability of prescribing an opioid and predicted morphine milligram equivalent (MME) dose by physician gender. Figure created by the authors. $(A, B)$ Predicted probability of opioid prescribing based on the following values for the multiple logistic generalised estimating equation (GEE) model regression coefficients: age of physician $=43.7$, physician region of practice $=$ South, analgesic/physiotherapy before $=1$, predicted confounder score $=0.15$; predicted confounder score $=26(C)$, physician specialty=primary care, physician citizenship=Asia. (C) Predicted MME opioid dose based on the following values for the multiple linear GEE regression coefficients: age of physician $=43.7$, physician region of practice $=$ South, analgesic/physiotherapy before $=1$, predicted confounder score=26, physician specialty=primary care, physician citizenship=Asia. those in medical (OR $0.34,95 \%$ CI 0.29 to 0.40 ) and surgical (OR $0.65,95 \%$ CI 0.52 to 0.82 ) specialties. Among hospital-based specialists, $72.4 \%$ were rehabilitation or pain management specialists. When opioids were prescribed, surgical (mean MME dose 40.2) and hospital-based specialists (mean MME dose 35.4) prescribed higher doses than primary care physicians (mean MME dose 23.9; adjusted difference surgeons: $11.62,95 \%$ CI 7.51 to 15.73 , hospital-based specialists: $9.80,95 \%$ CI 6.66 to 12.95 ).

Physicians whose practice was located in the northern (OR $0.63,95 \%$ CI 0.58 to 0.69 ) or western (OR $0.88,95 \%$ CI 0.80 to 0.96 ) USA were less likely to prescribe opioids compared with physicians in the South, although physicians in the West prescribed significantly higher doses (2.71 MME higher, 95\% CI 0.52 to 4.89 ). Patients who had previously received physiotherapy or non-steroidal anti-inflammatory drugs were $56 \%$ more likely to be prescribed an opioid (OR $1.56,95 \%$ CI 1.49 to 1.63 ).

\section{DISCUSSION}

This study is the first to investigate whether clinical competence, physician country of origin or training location are associated with opioid prescribing for common non-cancer-related pain problems. We found that physician gender modified the effect of clinical competence on opioid prescribing. More competent female physicians were less likely to prescribe opioids, and more competent male physicians prescribed higher doses. Country of origin did not influence the odds of opioid prescribing, but US and Canadian physicians prescribed opioids at significantly higher doses. Primary care physicians were more likely to prescribe opioids than medical and surgical specialties, but when opioids were prescribed, surgical and hospital-based specialties prescribed higher doses. Male physicians were more likely to prescribe opioids and at higher doses.

Standardised performance-based examinations such as the CSA were added to written examinations for licensure in Canada, the USA and the UK based on the need to measure both clinical and communication skills. ${ }^{40}$ Many medical schools also conduct this form of assessment for their students. ${ }^{65-67}$ Scores achieved on these assessments have been shown to predict quality of care, as well as complaints to and disciplinary action by medical regulatory authorities. ${ }^{2468-70}$ This study provided new insights about the contribution of clinical competence to opioid prescribing. Even though female physicians uniformly receive higher scores than male physicians in examinations that measure clinical knowledge, skills and communication, ${ }^{71-73}$ our findings suggest that greater proficiency in clinical, communication, and diagnostic and management skills has a different impact on opioid prescribing among male and female physicians. Higher scoring female physicians are more cautious about 


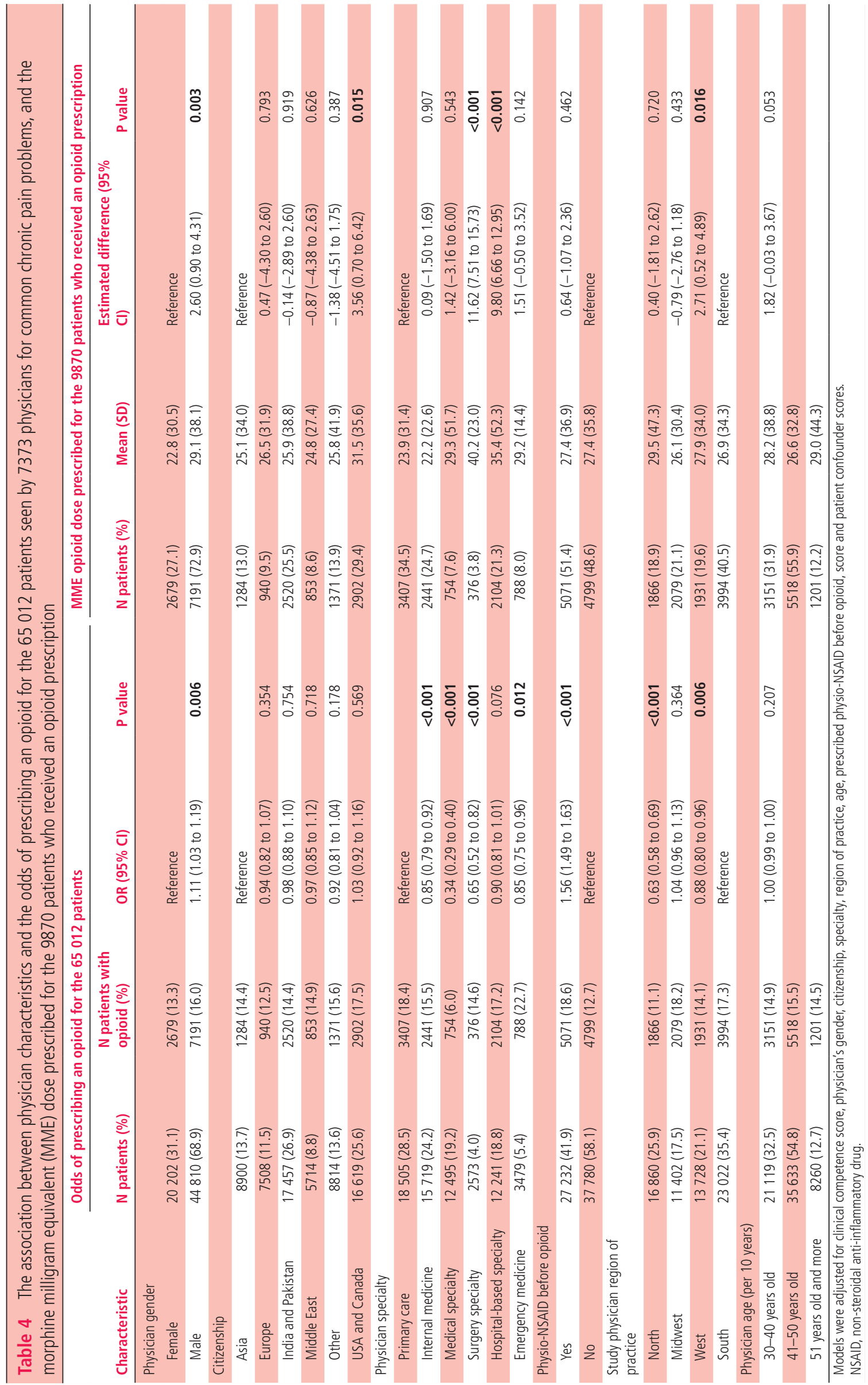


prescribing opioids, whereas higher scoring male physicians are more likely to prescribe more potent opioids and at higher doses. A similar phenomenon was reported in relationship to antibiotic prescribing for viral infections: higher scoring male physicians on the Canadian national standardised performance examination were more likely to prescribe antibiotics, whereas the opposite was true for female physicians. ${ }^{23}$ One possible explanation is that more competent male physicians provide more aggressive treatment while more competent female physicians are more conservative. While this particular hypothesis has not been investigated, female physicians prescribe lower starting doses of anti-cholinesterase inhibitors for patients with dementia and are more likely to screen patients for cardiac problems, ${ }^{26}$ refer a greater proportion of patients for specialty consultation, even after controlling for uncertainty and malpractice fear, ${ }^{27}$ and have higher rates of test ordering. ${ }^{28}$ A predisposition towards more aggressive treatment may also explain why more competent male physicians prescribe higher opioid doses, whereas more competent female physicians exhibit more caution in treatment decisions. These differences in the behaviour of male and female physicians are hypothesised to be related to fundamental differences in personality traits ${ }^{74}$ and risktaking behaviour. ${ }^{267576}$ Men are more likely to engage in riskier behaviour in fields such as finance and investment decision-making, ${ }^{77}$ driving ${ }^{76}{ }^{78}$ and gamblingdifferences that are seen even in childhood. ${ }^{79}$

Based on prior research that showed substantial differences in opioid prescribing practices of US and UK dentists, we hypothesised that cultural expectations for pain management may influence a physician's likelihood of opioid prescribing for common chronic pain problems. While there was considerable variation in the country of origin and training location of IMGs in this study, we did not find that this influenced opioid prescribing practices. The only exception was the significantly higher opioid doses prescribed by US and Canadian citizens. Direct-to-consumer drug advertising in the USA, coupled with a societal trend for improved pain management, ${ }^{15}$ 16-83 may explain these differences.

We found that primary care physicians and hospital-based specialties were more likely than other specialty groups to prescribe opioids for patients with chronic pain problems. Our findings are consistent with recent studies that showed a trend of reduced opioid prescribing by surgeons and emergency medicine physicians and increased opioid prescribing by primary care physicians and pain specialists. Unlike previous studies, ${ }^{43-45} 84$ we were able to show that these differences are not related to clinical competence or case mix, as we restricted the population of interest to patients who had been diagnosed with chronic pain problems by the study physician and adjusted for patient characteristics that influenced the likelihood of opioid prescribing. From a policy perspective, interventions to reduce the risk of opioid-related harms should be targeted at primary care physicians and pain specialists as well as surgical specialists as the latter prescribe substantially higher opioid doses, which increase the risk of opioid-related harms and long-term use. ${ }^{85-89}$

A number of limitations should be considered in interpreting the results of this study. Our study population was limited to Medicare patients with drug coverage. The prescribing trends observed in this population may not be representative of those for other patients in the physician's practice. However, we did find that factors that increased the risk of receiving an opioid were similar to those reported in other observational studies: back pain, receiving care in the ED, younger age, and having failed on prior conservative treatments such as non-opioid analgesics and physiotherapy. ${ }^{43} 616290$ Moreover, we noted that higher doses were prescribed by surgeons and hospital-based specialties, which has also been reported. ${ }^{45}{ }^{91}$ Higher rates of opioid prescribing are associated with regions with higher poverty and unemployment levels. ${ }^{92}$ We do not have patient-level measures of these attributes, which may contribute to residual confounding if physicians with lower competence levels were more likely to practise in these regions. It is also possible that patients migrate to physicians who are natives of the same country and cultural differences in patient expectation for opioids are contributing to opioid prescribing, which may contribute to residual confounding. The measurement of clinical competence took place 10 years before the assessment of opioid prescribing, and may not reflect current knowledge and skills. However, prior research has shown that performance-based examination test scores are associated with quality of care, even after 12 years in practice, ${ }^{23-25}$ which explains the observation that over $40 \%$ of the variance in maintenance of certification examination scores is explained by performance on the initial certification examination. The strong correlation between examination scores may explain why an association exists even after 10 years in practice. The CSA was replaced by USMLE Step 2, but the format of the examination and its psychometric properties are the same as the CSA, and thus our findings are relevant to standardised performance-based examinations. ${ }^{40-42729495}$ Although we had no measure of institutional protocols for opioid prescribing, there is wide variation in physician opioid prescribing, even in the same institution and for the same surgical procedure. ${ }^{9697}$ As our study was limited to ambulatory visits, mainly to primary care physicians and internists in private practice, institutional practices likely had limited impact. There may be other regional attributes of a physician's practice location that we did not measure that could influence their prescribing patterns. Finally, we had only proxy measures of cultural expectations for pain management, and this limitation needs 
to be addressed by better methods of measurement in future research.

\section{CONCLUSION}

In summary, greater clinical competence at the time of entry into US graduate medical training reduces the likelihood of prescribing opioids for common chronic non-cancer pain problems, but only among female physicians. While primary care physicians are more likely to prescribe opioids, surgical and hospital-based specialties prescribe higher starting doses, as do physicians from Canada and the USA.

\author{
Author affiliations \\ ${ }^{1}$ Department of Medicine and Department of Epidemiology and Biostatistics, \\ McGill University, Montreal, Quebec, Canada \\ ${ }^{2}$ Clinical and Health Informatics Research Group, McGill University, Montreal, \\ Quebec, Canada \\ ${ }^{3}$ Foundation for Advancement of International Medical Education and Research \\ (FAIMER), Philadelphia, Pennsylvania, USA \\ ${ }^{4}$ McGill University Montreal, Montreal, Quebec, Canada
}

Contributors All authors contributed to the concept and design of the study. JB obtained access to data. NG performed data analyses. All authors contributed to the interpretation of results. RT drafted the manuscript. All authors provided feedback on the intellectual content of the manuscript and read and approved the final manuscript. RT is the guarantor of this manuscript.

Funding This study was funded by the Foundation for Advancement of International Medical Education and Research (FAIMER), grant number not applicable.

Competing interests None declared.

Patient consent for publication Not required.

Ethics approval Ethics approval was provided by the McGill University Institutional Review Board.

Provenance and peer review Not commissioned; externally peer reviewed.

Data availability statement No data are available.

Supplemental material This content has been supplied by the author(s). It has not been vetted by BMJ Publishing Group Limited (BMJ) and may not have been peer-reviewed. Any opinions or recommendations discussed are solely those of the author(s) and are not endorsed by BMJ. BMJ disclaims all liability and responsibility arising from any reliance placed on the content. Where the content includes any translated material, BMJ does not warrant the accuracy and reliability of the translations (including but not limited to local regulations, clinical guidelines, terminology, drug names and drug dosages), and is not responsible for any error and/or omissions arising from translation and adaptation or otherwise.

Open access This is an open access article distributed in accordance with the Creative Commons Attribution Non Commercial (CC BY-NC 4.0) license, which permits others to distribute, remix, adapt, build upon this work noncommercially, and license their derivative works on different terms, provided the original work is properly cited, appropriate credit is given, any changes made indicated, and the use is noncommercial. See: http://creativecommons.org/licenses/by-nc/4. $0 /$.

\section{ORCID iDs}

Robyn Tamblyn http://orcid.org/0000-0003-0134-6954

Bettina Habib http://orcid.org/0000-0001-9570-1026

\section{REFERENCES}

1 Wilson N, Kariisa M, Seth P, et al. Drug and Opioid-Involved Overdose Deaths - United States, 2017-2018. MMWR Morb Mortal Wkly Rep 2020;69:290-7.

2 CDC. Drug overdose deaths: centers for disease control and prevention (CDC), 2020. Available: https://www.cdc.gov/ drugoverdose/data/statedeaths.html [Accessed 22 Oct 2020].

3 Shipton EA, Shipton EE, Shipton AJ. A review of the opioid epidemic: what do we do about it? Pain Ther 2018;7:23-36.

4 Berterame S, Erthal J, Thomas J, et al. Use of and barriers to access to opioid analgesics: a worldwide, regional, and national study. Lancet 2016;387:1644-56.

5 Ciccarone D. The triple wave epidemic: supply and demand drivers of the US opioid overdose crisis. Int J Drug Policy 2019;71:183-8.

6 Rose ME. Are prescription opioids driving the opioid crisis? assumptions vs facts. Pain Med 2018;19:793-807.

7 Kertesz SG. Turning the tide or RIPtide? the changing opioid epidemic. Subst Abus 2017;38:3-8.

8 Gleber R, Vilke GM, Castillo EM, et al. Trends in emergency physician opioid prescribing practices during the United States opioid crisis. Am J Emerg Med 2020;38:735-40.

9 Zhu W, Chernew ME, Sherry TB, et al. Initial opioid prescriptions among U.S. commercially insured patients, 2012-2017. N Engl J Med Overseas Ed 2019;380:1043-52.

10 Santosa KB, Wang CS, Hu H-M, et al. Surgeon experience and opioid prescribing. Am J Surg 2020;220:823-7.

11 Hooten WM, Dvorkin J, Warner NS, et al. Characteristics of physicians who prescribe opioids for chronic pain: a metanarrative systematic review. J Pain Res 2019;12:2261-89.

12 Inoue K, Figueroa JF, Orav EJ. Association between industry payments for opioid products and physicians' prescription of opioids: observational study with propensity-score matching. $J$ Epidemiol Community Health 2020;74:647-54.

13 Suda KJ, Durkin MJ, Calip GS, et al. Comparison of opioid prescribing by dentists in the United States and England. JAMA Netw Open 2019;2:e194303.

14 Kaafarani HMA, Han K, El Moheb M. Opioids after surgery in the United States versus the rest of the world: the International patterns of opioid prescribing (iPOP) multicenter study. Ann Surg 2020;272.

15 Chidgey BA, McGinigle KL, McNaull PP. When a vital sign leads a country Astray-The opioid epidemic. JAMA Surg 2019;154:987-8.

16 Rummans TA, Burton MC, Dawson NL. How good intentions contributed to bad outcomes: the opioid crisis. Mayo Clin Proc 2018;93:344-50.

17 Moore A, Grime J, Campbell P, et al. Troubling stoicism: sociocultural influences and applications to health and illness behaviour. Health 2013;17:159-73.

18 Hobara M. Beliefs about appropriate pain behavior: crosscultural and sex differences between Japanese and EuroAmericans. Eur J Pain 2005;9:389-93.

19 Pillay T, Zyl HAvan, Blackbeard D. Chronic pain perception and cultural experience. Procedia Soc Behav Sci 2014;113:151-60.

20 Galanti GA. Filipino attitudes toward pain medication. A lesson in cross-cultural care. West J Med 2000;173:278-9.

21 Wagstaff GF, Rowledge AM. Stoicism: its relation to gender, attitudes toward poverty, and reactions to emotive material. $J$ Soc Psychol 1995;135:181-4. 
22 Whelan GP. Educational Commission for foreign medical graduates: clinical skills assessment prototype. Med Teach 1999;21:156-60.

23 Cadieux G, Abrahamowicz M, Dauphinee D, et al. Are physicians with better clinical skills on licensing examinations less likely to prescribe antibiotics for viral respiratory infections in ambulatory care settings? Med Care 2011;49:156-65.

24 Tamblyn R, Abrahamowicz M, Dauphinee D, et al. Physician scores on a national clinical skills examination as predictors of complaints to medical regulatory authorities. JAMA 2007;298:993-1001.

25 Wenghofer E, Klass D, Abrahamowicz M, et al. Doctor scores on national qualifying examinations predict quality of care in future practice. Med Educ 2009;43:1166-73.

26 Rochon PA, Gruneir A, Bell CM, et al. Comparison of prescribing practices for older adults treated by female versus male physicians: a retrospective cohort study. PLoS One 2018;13:e0205524.

27 Franks P, Williams GC, Zwanziger J, et al. Why do physicians vary so widely in their referral rates? J Gen Intern Med 2000;15:163-8.

28 Cadogan SL, Browne JP, Bradley CP, et al. Physician and practice characteristics associated with immunoglobulin test ordering. Fam Pract 2018;35:41-6.

29 Tamblyn R, McLeod P, Hanley JA, et al. Physician and practice characteristics associated with the early utilization of new prescription drugs. Med Care 2003;41:895-908.

30 Rosso S, Battista RN, Segnan N, et al. Determinants of preventive practices of general practitioners in Torino, Italy. Am J Prev Med 1992;8:339-44.

31 Christian AH, Mills T, Simpson SL, et al. Quality of cardiovascular disease preventive care and physician/practice characteristics. J Gen Intern Med 2006;21:231-7.

32 Qaseem A, Wilt TJ, McLean RM, et al. Noninvasive treatments for acute, subacute, and chronic low back pain: a clinical practice guideline from the American College of physicians. Ann Intern Med 2017;166:514-30.

33 Hochberg MC, Altman RD, April KT, et al. American College of rheumatology 2012 recommendations for the use of nonpharmacologic and pharmacologic therapies in osteoarthritis of the hand, hip, and knee. Arthritis Care Res 2012;64:465-74.

34 O'Connor AB, Dworkin RH. Treatment of neuropathic pain: an overview of recent guidelines. Am J Med 2009;122:S22-32.

35 Reid KJ, Harker J, Bala MM, et al. Epidemiology of chronic non-cancer pain in Europe: narrative review of prevalence, pain treatments and pain impact. Curr Med Res Opin 2011;27:449-62.

36 GBD 2016 Disease and Injury Incidence and Prevalence Collaborators. Global, regional, and national incidence, prevalence, and years lived with disability for 328 diseases and injuries for 195 countries, 1990-2016: a systematic analysis for the global burden of disease study 2016. Lancet 2017;390:1211-59.

37 Schopflocher D, Taenzer P, Jovey R. The prevalence of chronic pain in Canada. Pain Res Manag 2011;16:445-50.

38 Lacasse A, Ware MA, Dorais M, et al. Is the Quebec provincial administrative database a valid source for research on chronic non-cancer pain? Pharmacoepidemiol Drug Saf 2015;24:980-90.
39 Reznick RK, Blackmore D, Dauphinée WD, et al. Large-scale high-stakes testing with an OSCE: report from the medical Council of Canada. Acad Med 1996;71:S19-21.

40 Boulet JR, Smee SM, Dillon GF, et al. The use of standardized patient assessments for certification and licensure decisions. Simul Healthc 2009;4:35-42.

41 Howley LD, Engle DL. Discontinuation of the USMLE step 2 clinical skills examination: studying the past to define the future. Acad Med 2021;96:1247-9.

42 Klass D, DeChamplain A, Fletcher E. Development of a performance-based test of clinical skills for the United States medical licensure examination. J Medical Licens Discip $1998 ; 85$.

43 Borgundvaag B, McLeod S, Khuu W, et al. Opioid prescribing and adverse events in opioid-naive patients treated by emergency physicians versus family physicians: a populationbased cohort study. CMAJ Open 2018;6:E110-7.

44 Weiner SG, Baker O, Rodgers AF, et al. Opioid prescriptions by specialty in Ohio, 2010-2014. Pain Med 2018;19:978-89.

45 Ringwalt C, Gugelmann H, Garrettson M, et al. Differential prescribing of opioid analgesics according to physician specialty for Medicaid patients with chronic noncancer pain diagnoses. Pain Res Manag 2014;19:179-85.

46 Nataraj N, Zhang K, Guy GP, et al. Identifying opioid prescribing patterns for high-volume prescribers via cluster analysis. Drug Alcohol Depend 2019;197:250-4.

47 Bertakis KD, Callahan EJ, Helms LJ, et al. Physician practice styles and patient outcomes: differences between family practice and general internal medicine. Med Care 1998;36:879-91.

48 Grumbach K, Selby JV, Schmittdiel JA, et al. Quality of primary care practice in a large HMO according to physician specialty. Health Serv Res 1999;34:485-502.

49 Chen J, Radford MJ, Wang Y, et al. Care and outcomes of elderly patients with acute myocardial infarction by physician specialty: the effects of comorbidity and functional limitations. Am J Med 2000;108:460-9.

50 Chin MH, Zhang JX, Merrell K. Specialty differences in the care of older patients with diabetes. Med Care 2000;38:131-40.

51 Yabroff KR, Saraiya M, Meissner HI, et al. Specialty differences in primary care physician reports of Papanicolaou test screening practices: a national survey, 2006 to 2007. Ann Intern Med 2009;151:602-11.

52 Chou R, Qaseem A, Snow V, et al. Diagnosis and treatment of low back pain: a joint clinical practice guideline from the American College of physicians and the American pain Society. Ann Intern Med 2007;147:478-91.

53 Dagenais S, Tricco AC, Haldeman S. Synthesis of recommendations for the assessment and management of low back pain from recent clinical practice guidelines. Spine J 2010;10:514-29.

54 Dowell D, Haegerich TM, Chou R. CDC Guideline for Prescribing Opioids for Chronic Pain-United States, 2016. JAMA 2016;315:1624-45.

55 Deepmala D, Franz L, Aponte C, et al. Identification of provider characteristics influencing prescription of analgesics: a systematic literature review. Pain Pract 2013;13:504-13.

56 Bartley EJ, Boissoneault J, Vargovich AM, et al. The influence of health care professional characteristics on pain management decisions. Pain Med 2015;16:99-111. 
57 Dhalla IA, Mamdani MM, Gomes T, et al. Clustering of opioid prescribing and opioid-related mortality among family physicians in Ontario. Can Fam Physician 2011;57:e92.

58 Varney SM, Bebarta VS, Mannina LM, et al. Emergency medicine providers' opioid prescribing practices stratified by gender, age, and years in practice. World J Emerg Med 2016;7:106-10.

59 McDonald DC, Carlson K, Izrael D. Geographic variation in opioid prescribing in the U.S. J Pain 2012;13:988-96.

60 St Clair CO, Golub NI, Ma Y, et al. Characteristics associated with U.S. outpatient opioid analgesic prescribing and Gabapentinoid co-prescribing. Am J Prev Med 2020;58:e11-19.

61 McCann-Pineo M, Ruskin J, Rasul R, et al. Predictors of emergency department opioid administration and prescribing: a machine learning approach. Am J Emerg Med 2021;46:217-24.

62 Urman RD, Böing EA, Khangulov V, et al. Analysis of predictors of opioid-free analgesia for management of acute post-surgical pain in the United States. Curr Med Res Opin 2019;35:283-9.

63 Shao Q, Rascati KL, Lawson KA, et al. Patterns and predictors of opioid use among migraine patients at emergency departments: a retrospective database analysis. Cephalalgia 2020;40:1489-501.

64 Breckenridge J, Clark JD. Patient characteristics associated with opioid versus nonsteroidal anti-inflammatory drug management of chronic low back pain. J Pain 2003;4:344-50.

65 Howley LD, Gliva-McConvey G, Thornton J, et al. Standardized patient practices: initial report on the survey of US and Canadian medical schools. Med Educ Online 2009; $14: 7$.

66 Petrusa ER. Taking standardized patient-based examinations to the next level. Teach Learn Med 2004;16:98-110.

67 Hauer KE, Teherani A, Kerr KM, et al. Consequences within medical schools for students with poor performance on a medical school standardized patient comprehensive assessment. Acad Med 2009;84:663-8.

68 Cuddy MM, Young A, Gelman A. Exploring the relationships between USMLE performance and disciplinary action in practice: a validity study of score inferences from a licensure examination. Acad Med 2017;92:1780-5.

69 Kawasumi Y, Ernst P, Abrahamowicz M, et al. Association between physician competence at licensure and the quality of asthma management among patients with out-of-control asthma. Arch Intern Med 2011;171:1292-4.

70 Tamblyn R, Abrahamowicz M, Dauphinee WD, et al. Association between licensure examination scores and practice in primary care. JAMA 2002;288:3019-26.

71 Graf J, Smolka R, Simoes E, et al. Communication skills of medical students during the OSCE: gender-specific differences in a longitudinal trend study. BMC Med Educ 2017;17:75.

72 van Zanten M, Boulet JR, McKinley DW, et al. Assessing the communication and interpersonal skills of graduates of international medical schools as part of the United States medical licensing exam (USMLE) step 2 clinical skills (CS) exam. Acad Med 2007;82:S65-8.

73 Swygert KA, Cuddy MM, van Zanten M, et al. Gender differences in examinee performance on the step 2 clinical skills data gathering $(\mathrm{dG})$ and patient note $(\mathrm{PN})$ components. Adv Health Sci Educ Theory Pract 2012;17:557-71.

74 Feingold A. Gender differences in personality: a meta-analysis. Psychol Bull 1994;116:429-56.
75 Hardies K, Breesch D, Branson J. Gender differences in overconfidence and risk taking: do self-selection and socialization matter? Econ Lett 2013;118:442-4.

76 Byrnes JP, Miller DC, Schafer WD. Gender differences in risk taking: a meta-analysis. Psychol Bull 1999;125:367-83.

77 Charness G, Gneezy U. Strong evidence for gender differences in risk taking. J Econ Behav Organ 2012;83:50-8.

78 Turner C, McClure R. Age and gender differences in risktaking behaviour as an explanation for high incidence of motor vehicle crashes as a driver in young males. Inj Control Saf Promot 2003;10:123-30.

79 Cárdenas J-C, Dreber A, von Essen E, et al. Gender differences in competitiveness and risk taking: comparing children in Colombia and Sweden. J Econ Behav Organ 2012;83:11-23.

80 Dasgupta N, Beletsky L, Ciccarone D. Opioid crisis: no easy fix to its social and economic determinants. Am J Public Health 2018;108:182-6.

81 Vadivelu N, Kai AM, Kodumudi V, et al. The opioid crisis: a comprehensive overview. Curr Pain Headache Rep 2018;22:16.

82 Fain KM, Alexander GC. Mind the gap: understanding the effects of pharmaceutical direct-to-consumer advertising. Med Care 2014;52:291-3.

83 Schwartz LM, Woloshin S. Medical marketing in the United States, 1997-2016. JAMA 2019;321:80-96.

84 Guy GP, Zhang K. Opioid prescribing by specialty and volume in the U.S. Am J Prev Med 2018;55:e153-5.

85 Gomes T, Mamdani MM, Dhalla IA, et al. Opioid dose and drug-related mortality in patients with nonmalignant pain. Arch Intern Med 2011;171:686-91.

86 Oderda GM, Said Q, Evans RS, et al. Opioid-related adverse drug events in surgical hospitalizations: impact on costs and length of stay. Ann Pharmacother 2007;41:400-7.

87 Liang Y, Turner BJ. National cohort study of opioid analgesic dose and risk of future hospitalization. J Hosp Med 2015;10:425-31.

88 Deyo RA, Hallvik SE, Hildebran C, et al. Association between initial opioid prescribing patterns and subsequent long-term use among Opioid-Naïve patients: a statewide retrospective cohort study. J Gen Intern Med 2017;32:21-7.

89 Shah A, Hayes CJ, Martin BC. Characteristics of Initial Prescription Episodes and Likelihood of Long-Term Opioid Use - United States, 2006-2015. MMWR Morb Mortal Wkly Rep 2017;66:265-9.

90 Rasu RS, Knell ME. Determinants of opioid prescribing for nonmalignant chronic pain in US outpatient settings. Pain Med 2018;19:524-32.

91 Cron DC, Lee JS, Dupree JM, et al. Provider characteristics associated with outpatient opioid prescribing after surgery. Ann Surg 2020;271:680-5.

92 Guy GP, Zhang JX, Bohm M. Vital signs: changes in opioid prescribing in the United States, 2006-2015, 2017: 697-704.

93 Zhou C, Yu NN, Losby JL. The association between local economic conditions and opioid prescriptions among disabled Medicare beneficiaries. Med Care 2018;56:62-8.

94 Ayers WR, Boulet JR. Establishing the validity of test score inferences: performance of 4th-year U.S. medical students on the ECFMG clinical skills assessment. Teach Learn Med 2001;13:214-20.

95 van Zanten M, Boulet JR, McKinley D. Using standardized patients to assess the interpersonal skills of physicians: six years' experience with a high-stakes certification examination. Health Commun 2007;22:195-205. 
96 Barnett ML, Olenski AR, Jena AB. Opioid-Prescribing patterns of emergency physicians and risk of long-term use. N Engl J Med Overseas Ed 2017;376:663-73.
97 Sabatino MJ, Kunkel ST, Ramkumar DB, et al. Excess opioid medication and variation in prescribing patterns following common orthopaedic procedures. J Bone Joint Surg Am 2018;100:180-8. 